\title{
PERCEPÇÃO DOS GENITORES SOBRE O IMPACTO DO NASCIMENTO DO SEGUNDO FILHO NAS RELAÇÕES FAMILIARES
}

\author{
PERCEPTION OF GENITORS ON THE IMPACT OF THE SECOND CHILD'S \\ BIRTH IN THE FAMILY RELATIONSHIPS
}

\section{BIBIANA UGHINI GOLDSCHMIDT}

Universidade do Sul de Santa Catarina (Unisul), Palhoça/ SC, Brasil
RESUMO: As famílias passam por ciclos de vida que podem demandar adaptações, sendo a inserção de um novo membro no contexto familiar um deles. No presente estudo, foram investigados os impactos do nascimento do segundo filho nas relações: genitores-primogênito, relação conjugal, impacto no próprio filho mais velho e nos genitores. Para isso, foram realizadas entrevistas com três casais que atendiam aos requisitos da pesquisa. Pôde-se identificar, na análise, alguns aspectos, como 0 afastamento dos casais em relação a atividades a dois, que o comportamento mais frequente demonstrado pelo primogênito foi de chamar atenção dos pais para ele. Demonstrou-se, também, uma aproximação dos pais em relação ao filho mais velho e as mães apresentaram uma necessidade maior de organização com a chegada do segundo filho. As estratégias de manejo mais salientadas foram de contar com a rede de apoio, principalmente com os avós maternos, e investir no diálogo com o primogênito.

PALAVRAS-CHAVE: Primogênito; Segundo Filho; Relações Familiares.
ABSTRACT: Families go through several life cycles that may demand adaptations, with the insertion of a new member in the family context being one of them. In this study, the impacts of the birth of the second child on family relationships were investigated, focusing on the first-born child contact, marital relationship, impact on the eldest child and on the parents. To this end, interviews were conducted with three couples who met the research requirements. In the analysis, it is possible to identify some aspects such as the separation of couples in relation to activities for two, the most frequent behavior demonstrated by the firstborn was to draw the attention of parents to it, there is an approximation of fathers in relation to the eldest child and mothers feel a greater need for organization with the arrival of the second child. Finally, the most presented management strategies were to rely on the support network, especially with the maternal grandparents and to invest in dialogue with the firstborn.

KEYWORDS: Firstborn; Second child; Family relations
Recebido em: 09/05/2019 Aprovado em: 20/09/2019

\section{INTRODUÇÃO}

As famílias vêm sofrendo mudanças significativas no que se refere à sua estrutura e relações familiares, especialmente por consequência das novas formas de trabalho na sociedade contemporânea e das inúmeras transformações na ecologia da família, ocasionadas por mudanças sociais, econômicas e culturais. Novas crenças e condutas sobre os papéis de pai e mãe têm sido possibilitadas por aspectos como o movimento feminista e a saída progressiva da mulher do ambiente e prática doméstica para uma maior atividade no mercado de trabalho (Gomes, Bossardi, Cruz, Crepaldi, \& Vieira, 2014). A dinâmica da família apresenta-se 
mais flexível, onde homens e mulheres possam transitar por vários papéis (cuidador; profissional; mãe; pai etc.), a mulher possa ser a provedora e o homem assumir o papel de cuidados ao lar e aos filhos (Beltrame \& Bottoli 2010). Como resultado desses aspectos vem se estabelecendo uma combinação de padrões de relações familiares onde há articulação nos papéis de cada membro do conjunto familiar e valorização dos laços de afeto e fraternidade (Scaglia, Mishima-Gomes, \& Barbieri, 2018).

As configurações familiares também sofreram modificações ao longo dos anos, por isso, pode-se encontrar famílias que se configuram com um só responsável coabitando com a(s) criança(s), caracterizadas como famílias monoparentais (Oliveira, 2009). Existem também casais que optam por não terem filhos, avós que fazem o papel materno e paterno dos netos, homoparentalidade (constituída por casais homoafetivos), casais separados/divorciados, casais heterossexuais etc. (Lobo, 2009). Porém, de acordo com Felippi e Itaqui (2015), apesar da diversidade de configurações familiares e do conceito de família ser um conjunto em constante transformação, ainda hoje há a predominância das famílias de casais heterossexuais e nucleares. Estas são caracterizadas por um homem e uma mulher unidos por um casamento/união estável, que moram na mesma residência e geraram filhos desta união (Ariés, 1977).

Scaglia et al. (2018) relatam que o processo de transformação das famílias é constante, e ao longo dos anos sofre ação da economia e do sistema tecnológico. Scavone (2001) relata que a integração da economia possibilitou novos padrões de comportamentos de consumo. No caso das mulheres que passaram a utilizar mais constantemente as tecnologias contraceptivas, foi oportunizada a escolha/liberdade referente à maternidade, abrindo espaço para o dilema de ser ou não ser mãe. Dessa forma, a mulher contemporânea é independente e mais ativa, tanto emocional como financeiramente, além de apresentar uma maior liberdade sexual (Staudt \& Wagner, 2008).

Essas mudanças acarretaram também uma redefinição no papel masculino, que possibilitou maior demonstração de afetividade e fragilidades (Silva, Bueno, \& Ribeiro, 2014), impulsionando homens a terem uma maior participação no contexto doméstico e na criação de filhos (Cúnico \& Arpini, 2013). O retrato atual revela homens e mulheres com muita demanda na área profissional e familiar, e pouco tempo para ter e manter relações de qualidade. A situação fica ainda mais complexa quando estes decidem ter o primeiro filho, visto que, nesse contexto, o orçamento diminui, as obrigações aumentam e os casais ficam ainda mais sobrecarregados (Carter \& Mcgoldrick, 1989/2001; Hansen, 2012; Pollman-Schult, 2014). O casal contemporâneo procura estabelecer uma qualidade de vida nos aspectos econômicos antes de ter filhos, fator que pode postergar o "tornar-se" pais e mães (Hansen, 2012; Pollman-Schult, 2014). Quando a criança cresce, e a situação financeira e social parece voltar a se estabilizar, pode surgir a vontade de ter o segundo filho, porém, na maior parte das vezes, não acontece. Rocha-Coutinho (2015) relata que o lugar das famílias numerosas que encontrávamos no passado foi tomado pelo número reduzido de membros, bem como a diminuição da população em geral.

Para a família contemporânea, onde a demarcação dos papéis masculinos e 
femininos é menos sólida e a ideia de família nuclear mantém-se (Felippi \& Itaqui, 2015), a batalha ao se ter filhos é o manejo das tarefas e responsabilidades frente à família, podendo ser considerada a maior dificuldade neste ciclo vital (Walsh, 2016). Piccinini et al. (2007) relatam que, no caso de se ter o segundo filho, o medo de passar pelas situações de estresse novamente, de não conseguir manejar e criar uma segunda criança e o excesso de tarefas acabam por assustar muitas vezes as famílias, e as faz optar por não o conceber. Os autores acrescentam que, com a falta de tempo disponível desses casais, nem sempre se consegue estabelecer qualidade nas relações familiares, e a manutenção destas fica precária, gerando conflitos ainda maiores que esses pais não estão dispostos a enfrentar nem preparados para lidar.

A inserção desse novo membro na família pode acarretar implicações sociais, econômicas e emocionais, afetando todos os membros de maneiras diferentes (Oliveira \& Lopes, 2010), modificando as relações e acabando por exigir a reformulação dos papéis dentro da família nuclear, como relatam Pereira e Piccinini (2007). Os pais passam a ser "pais de dois filhos" e o filho único assume a responsabilidade de irmão mais velho (Pereira \& Piccinini, 2007; Walz \& Rich, 1983). Além disso, Carter e McGoldrick (1989/2001) definem esse momento de passagem de um sistema triádico (mãe, pai e filho) para um sistema poliádico (pais e filhos) (Dessen, 1997) como um acontecimento nodal, ou seja, capaz de gerar instabilidade e aumentar o nível de estresse dos membros constituintes da família. Adams (1985) acrescenta que o sistema familiar torna-se mais complexo, pois o número de relações duplica de três para seis (relação conjugal, mãe-primogê- nito, pai-primogênito, mãe-segundo filho, pai-segundo filho e relação fraterna), podendo trazer desequilíbrio e demandando uma reorganização do sistema como um todo (Dessen, 1997; Pereira \& Piccinini, 2007).

De acordo com pesquisas de Carter, McGoldrick e Petkov (2011, citados por Walsh, 2012), quando os casais se tornam pais, há um alto índice de decréscimo na qualidade das relações conjugais, diminuindo a satisfação de um com o outro, devido, principalmente, ao acúmulo de preocupações com o bebê e o pouco tempo para intimidade do casal (Carter \& Mcgoldrick, 1989/2001; Piccinini et al., 2007). Além desses aspectos, o primogênito também aparece como sujeito afetado, visto que sua relação com os genitores é modificada a partir da chegada de um novo componente na família nuclear (Dunn \& Kendrick, 1986). Dessen (1997) acrescenta que o primogênito também pode passar a apresentar comportamentos ambivalentes, de atitudes independentes em alguns momentos, e em outros sinalizando que gostaria de receber o mesmo cuidado que o novo membro familiar, o bebê. A autora relata que o papel de pai pode se tornar mais ativo nessa fase do ciclo familiar, e sua relação com o primogênito pode ser fortalecida. Já a relação entre os irmãos pode variar entre rivalidade e comportamentos agressivos, e afetividade (Dessen, 1997).

De todos os impactos da chegada do segundo filho, Oliveira e Lopes (2010) relatam que a relação mais afetada é mãe-primogênito, e verificam que há uma diminuição de apego. $\mathrm{O}$ motivo seria o excesso de atividades que demanda ser mãe de um bebê, mãe de um filho mais velho, esposa, profissional e atender às suas próprias necessidades - fazendo com que justamente a falta de tempo e energia recaia nessa 
relação com o primogênito. As mães podem ficar mais restritivas e ansiosas com o primogênito, com medo de que alguma ação dele possa vir a machucar o bebê (Dunn \& Kendrick, 1980) e o filho mais velho pode vir a agir de maneira mais agressiva, confrontando a mãe com mais frequência (Baydar, Greek, \& Brooks-Gunn, 1997).

Esses impactos nas relações são observados a partir das fases do ciclo de vida pelos quais as famílias passam, fazendo-as se modificarem e se reorganizarem. Os ciclos podem ser marcados por estressores, verticais e/ou horizontais. Os primeiros (estressores verticais), de acordo com Carter e McGoldrick (1989/2001), são os mitos e padrões de comportamento de cada família, que são transferidos de acordo com as épocas e passar das gerações, incluem atitudes, expectativas e rótulos e carregam a história familiar (Walsh, 2016). Já os estressores horizontais são aqueles previsíveis e têm relação com o desenvolvimento familiar à medida que progride no tempo, como a morte, doença, perda de emprego e como no caso de se ter um filho (Carter \& Mcgoldrick, 1989/2001; Walsh, 2016). Dessa forma, os conjuntos familiares são definidos por pessoas que possuem uma história compartilhada, unidas por um laço de sangue, legais e/ ou históricos, em constante mudança (Walsh, 2016).

Por mais que a família seja um sistema integrado, ela acaba possuindo divisões no que diz respeito aos subsistemas familiares (Pontes, Silva, Garotti, \& Magalhães, 2007). Numa família: pai, mãe e dois filhos, têm-se as relações diádicas: conjugal, mãe-primogênito, pai-primogênito, mãe-segundo filho, pai-segundo filho e relação fraterna. Encontra-se também a relação triádica coparental, caracteriazada por dois adultos cuidadores e pelo menos uma criança. Essas relações são geradoras de vínculos, laços afetivos que conectam os membros da família e contribuem para um equilíbrio e organização do grupo familiar (Cardoso \& Veríssimo, 2013) e, para compreender um melhor funcionamento do sistema familiar, é necessário compreender os elos sistêmicos que fazem parte dos diferentes subsistemas familiares (Pontes et al., 2007).

O contexto familiar serve de apoio, é estimulador e gerador de afeto, orienta e educa, além de auxiliar nos cuidados essenciais. Justamente pelo fato de a família ser o primeiro espaço mais influente de socialização para uma criança no começo de vida, se faz muito importante como forma de auxílio no seu desenvolvimento geral (cultural, comportamental, ético, emocional) (Pereira, Ramos, \& Silveira, 2016). Portanto, a família é parte central para a constituição do sujeito, tanto nos aspectos individuais como sociais (Bowlby, 2006). Pode-se dizer, então, que é um sistema que se move no tempo, de forma espiral, sofrendo constantes atualizações que impactam na sua dinâmica (Oliveira, 2009).

Tendo em vista a importância da família na constituição dos sujeitos e as relações estabelecidas nesse meio, a presente pesquisa possui como objetivo geral caracterizar o impacto do nascimento do segundo filho nas relações da família nuclear a partir da percepção de pais e mães. E como objetivos específicos, identificar o impacto do nascimento do segundo filho na relação conjugal de acordo com a percepção de pais e mães; verificar o impacto nos genitores e relação genitores-primogênito com a chegada do segundo filho/a a partir da percepção de pais e mães; observar o impacto do nascimento do segundo filho no primogênito de acordo com a percepção 
de pais e mães; identificar as estratégias de manejo de pais e mães para lidar com esse período de mudança.

\section{MÉTODO}

A pesquisa é de caráter descritivo, e corte transversal. O procedimento utilizado foi ex-pós-facto e a abordagem é qualitativa. Participaram da pesquisa três casais de classe média (Quadro 1), contatados através da rede de relacionamentos interpessoais da pesquisadora e também por meio do uso de um cartaz virtual divulgado em redes sociais. Os critérios de inclusão dos participantes foram: casais heterossexuais com famílias nucleares; que tiveram dois filhos do mesmo casamento; as crianças não apresentassem doenças e tivessem que ter intervalos de idade entre 1 e 3 anos, já que estudos demonstram que crianças que estão em idade pré-escolar (2 a 4 anos) possuem mais dificuldades de adaptação quanto à chegada de um novo irmão (Oliveira, Pereira, Lopes, Bandeira \& Piccinini, 2016). Além disso, a experiência de tornar-se irmão mais velho é muito mais frequente na fase pré-escolar (Legg, Sherick, \& Wadland, 1974, citados por Oliveira \& Lopes, 2010).

Quadro 1 - Caracterização dos participantes Legenda: $\mathrm{P}=$ primogênito(a); $\mathrm{S}=\operatorname{segundo(a)}$ filho(a)

\begin{tabular}{|l|l|l|l|}
\hline CASAL & IDADE DO CASAL & PROFISSÕES & FILHOS \\
\hline Copa (C) & Pai (44) Mãe (41) & $\begin{array}{l}\text { Psicóloga (Mãe) } \\
\text { Engenheiro (Pai) }\end{array}$ & $\begin{array}{l}\text { P (10) menino / } \\
\text { S (8) menino }\end{array}$ \\
\hline Tronco (T) & Pai (37) Mãe (33) & $\begin{array}{l}\text { Professora (Mãe) } \\
\text { Administrador (Pai) }\end{array}$ & $\begin{array}{l}\text { P (8) menino / } \\
\text { S (4) menina }\end{array}$ \\
\hline Raiz (R) & Pai (36) Mãe (38) & $\begin{array}{l}\text { Contadora (Mãe) } \\
\text { Contador (Pai) }\end{array}$ & $\begin{array}{l}\text { P (6) menina / } \\
\text { S (2) menino }\end{array}$ \\
\hline
\end{tabular}

Fonte: Elaboração da autora (2018)

Os nomes para identificação dos casais foram escolhidos pelo fato de a árvore ser símbolo de vida e de constante mutação, como as famílias. A divisão entre copa, tronco e raiz foi feita a partir da estrutura econômica de cada casal, bem como valores perpetuados em cada uma delas, sendo raiz relacionados com crenças mais tradicionais e copa sendo os menos tradicionais. Os filhos dos casais tronco e raiz possuem diferença de idade de três anos e seis meses, e três anos e nove meses respectivamente. Dessa forma, como ainda se encontrava na faixa de intervalo de idade decidido nos requisitos da pesquisa, optou-se por mantê-los no estudo.
O instrumento de coleta de dados foi um roteiro de entrevista semiestruturada com vinte e duas questões, relacionadas com os objetivos específicos da pesquisa. O procedimento de coleta de dados iniciou-se com a explicação da pesquisa e o objetivo da mesma, e em seguida foi fornecido um Termo de Consentimento Livre e Esclarecido (TCLE) para autorização da gravação de áudio da entrevista e especificação da participação de cada entrevistado no processo de estudo. Após, foram coletados dados de identificação: nome; idade; profissão e escolaridade dos participantes, e idade atual e nome dos filhos do casal. 
As entrevistas realizadas tiveram em média a duração de 40 minutos e obtiveram a participação de ambos os membros do casal. A entrevista realizada com o casal RAIZ foi no ambiente laboral dos mesmos, fora do horário de trabalho, e com os casais TRONCO e COPA, a coleta de dados ocorreu na residência de cada um. Foi realizada análise de conteúdo categorial temático, com base em Bardin (1977), organizada em três etapas: pré-análise (leitura, escolha do material, formulação de hipóteses e indicadores), exploração do material (definição de categorias) e tratamento dos resultados (interpretação e análise crítica). A pesquisa obteve aprovação do Comitê de Ética e Pesquisa sob número de parecer 2.882.838.

\section{ANÁLISE}

Com base na interpretação dos dados da entrevista, foram estabelecidos quatro eixos embasados nos objetivos específicos da pesquisa. O Eixo I diz respeito ao impacto do nascimento do segundo filho na relação conjugal e abrange as categorias: Rotina do casal e Aspectos emocionais do casal. O Eixo II engloba o impacto no primogênito a partir de três categorias: Aspectos relacionais; Equilíbrio psicossomático e Aspectos desenvolvimentais. O Eixo III retrata impacto nos genitores e na relação genitores-primogênito, e divide-se em três categorias: impacto nas mães, impacto no pai e impacto na relação pais e mães com o primogênito. E por fim, o Eixo VI retrata as estratégias de manejo encontradas pelos casais para lidar com esse momento de mudança, sendo dividido em duas categorias: estratégias de manejo em relação à qualidade da relação conjugal, e em relação ao primogênito.
Eixo I - Impacto do nascimento do segundo filho na relação conjugal

$\mathrm{Na}$ categoria mudanças na rotina dos casais foram levados em consideração aspectos como o tempo em que passam juntos, e como o aproveitam. Dessa maneira, foram definidas cinco subcategorias, sendo a primeira delas diminuições de saídas para jantar, a qual foi referida por dois casais, $\mathrm{C} \mathrm{e}$ T. Porém, o casal $(\mathrm{T})$ acrescenta que, mesmo com as diminuições de saídas a dois, quando querem, ambos conseguem gerir - "A gente nunca mais foi num barzinho ou coisas assim, mas quando quer dá pra administrar" (mãe T). Sobre diminuição de viagens a dois, dois casais ressaltaram essa questão, porém um deles relata que isso aconteceu somente até o segundo filho fazer um ano (casal C), sendo que o outro casal ( $\mathrm{T}$ ) relata que só viaja com a família completa. A literatura retrata que o momento de chegada do segundo filho é capaz de gerar mudanças na relação conjugal, principalmente relacionadas à diminuição do tempo para atividades do casal (Piccinini et al., 2007). Outra subcategoria que surgiu durante a análise foi a de que quando o casal sai procura voltar mais cedo em função dos filhos, porém este aspecto apareceu somente no casal (T). Piccinini et al. (2007) relatam que, nesse momento, os pais sentem um maior envolvimento com os filhos, fator que pode contribuir, por exemplo, para retornar mais cedo de um evento ou até deixar de comparecer ao mesmo. Por fim, a última subcategoria foi definida por apenas um casal (R), relatando que sair só uma noite não é tão interessante, visto que não há tempo suficiente para um descanso propriamente dito, dessa maneira, quando o casal sai, sente a necessidade de ficar mais tempo fora. 
A chegada do segundo filho geralmente apresenta mais aspectos positivos na vida conjugal do que negativos, principalmente em relação à união do casal (Belsky, Spanier, \& Rovine, 1983 citado por Volling, 2012).

$\mathrm{Na}$ categoria, voltada para as mudanças nos aspectos emocionais do casal com a chegada do segundo filho, o intuito era de abranger principalmente sentimentos do casal associados à relação conjugal, porém, as respostas de ambos os membros do casal se voltaram para os papéis de mãe e pai, bem como emoções e sentimentos relacionados aos filhos. Dessa forma, a categoria foi dividida em duas subcategorias, sendo elas: receio de deixar os filhos com outras pessoas, e o fato de os pais e mães se sentirem mais protetores em relação aos filhos. O primeiro fator apareceu somente para o casal (C) e o segundo para o casal (T) - "Me pesava mais a coisa de deixar com um estranho, a confiança..." (mãe C). Tais aspectos podem estar relacionados com a necessidade de um maior envolvimento dos pais com os filhos nesse momento de vida (Piccinini et al. 2007), valorizando a adaptação à fase.

Diante das informações obtidas neste eixo, pode-se perceber que os momentos a dois dos casais diminuíram, salientando a falta de idas a jantares ou viagens, que pode ter relação com o fato de os pais se sentirem mais protetores. A satisfação conjugal permeia uma multiplicidade de fatores que podem estar associados ao ciclo vital do momento. No caso de tornarem-se pais e mães, a satisfação conjugal pode se apresentar vinculada à satisfação parental e no que o casal alcança em conjunto enquanto pais, valorizando suporte, apoio e decisões em coletivo (Scorsolini-Comin \& Santos, 2010; Rolim \& Wendling, 2013).
Eixo II - Impacto do nascimento do segundo filho no primogênito

Definiu-se a categoria impacto nos aspectos relacionais no primogênito. A partir dela, foram definidas três subcategorias voltadas principalmente para comportamentos e emoções do filho mais velho. Dois casais (C e R) apontaram manifestações de agressividade do primogênito, sendo que um deles (C) relatou essas manifestações tanto para com um de seus genitores, como para o irmão mais novo, e o outro (R) identificou esses aspectos somente direcionados ao irmão mais novo. De acordo com Field e Reite (1984), há um aumento significativo na agressividade dos primogênitos com a chegada de um irmão, seguido de comportamentos inadequados com os pais, e Piccinini et al. (2007) corroboram esse dado. Apenas um casal relatou que percebeu que o primogênito valorizou a chegada do irmão mais novo. Por fim, foi observado que em todos os três casais houve relatos de que o primogênito passou a ter comportamentos para chamar atenção, principalmente quando recebiam visitas em casa - "No começo quando as visitas vinham, ele falava mais alto pra chamar atenção" (mãe T). Este aspecto é salientado pelo estudo de Stewart, Mobley, Van-Tuyl \& Salvador (1987), que retratam que o primogênito aumenta o diálogo com os pais a fim de distraí-los do irmão mais novo e ganhar a atenção dos mesmos.

Outra categoria definida foi o impacto no equilíbrio psicossomático do filho mais velho, sendo que dois casais ( $\mathrm{C}$ e $\mathrm{T}$ ) perceberam essas situações - "No dia do nascimento da S o P teve uma febre muito alta (...) o médico disse que era emocional" (mãe T). Nos estudos de Piccinini et al. (2007), os autores apontam que sintomas físicos 
no primogênito foram relatados diante da chegada de um irmão mais novo, sendo febre alta um fator comum.

$\mathrm{Na}$ categoria direcionada aos aspectos desenvolvimentais do primogênito, abrangeu-se principalmente mudanças comportamentais observáveis pelos pais, dividindo-a em três subcategorias. Dois casais ( $\mathrm{T} \mathrm{e} \mathrm{C}$ ) perceberam mudanças no filho mais velho relacionadas com a regressão de comportamento "Ele (P) já tava no processo de desfralde e ele regrediu (...) aquela coisa clássica" (mãe C). A regressão é salientada no sentido de demandar mais dos pais em relação a alimentação e a higiene, demonstrando uma maior dependência (Legg, Sherick, \& Wadland, 1974 citados por Oliveira \& Lopes, 2010). Um dos casais entrevistados, no entanto, salientou a aquisição de aspectos como independência e autonomia do primogênito. Por fim, foi relatado por dois casais (T e R) a percepção de aumento da responsabilidade dos filhos mais velhos. Para Gottlieb e Baillies (1995 citados por Oliveira \& Lopes, 2010), há uma ambivalência de comportamentos do primogênito diante da chegada de um irmão, ora sendo de regressão, ora sendo de independência e autonomia.

No eixo II foram percebidos que os comportamentos mais frequentes do primogênito com a chegada do irmão seriam atitudes para chamar atenção dos pais e mães, principalmente quando o segundo filho recebia visita de familiares. Ou seja, o impacto no filho mais velho possui relação direta com a dinâmica do mesmo com os pais e mães. Dessa forma, pode-se compreender a possibilidade de uma melhor adaptação do primogênito com a chegada do irmão mais novo quando os pais e mães buscam inserí-lo no contexto, conversando sobre as mudanças e possibilitando um espaço de troca positivo para as redefinições das rela- ções. A relação com mais restrições e menos diálogo tende a revelar um impacto predominantemente negativo no primogênito, dificultando a sua adaptação com o irmão mais novo (Pereira \& Piccinini, 2007).

Eixo III - Impacto do nascimento do segundo filho nos genitores e na relação genitores-primogênito

A categoria voltada para o impacto na mãe abrange a própria percepção da mãe diante das suas alterações emocionais e mudanças de rotina durante esse ciclo vital. Dessa maneira, formou-se seis subcategorias, sendo elas destacadas como menos tempo de sono, fator relatado por uma mãe (C); exigência de uma maior organização na rotina, relatado por duas mães $(\mathrm{C} \mathrm{e}$ R) - "Tenho que estar com tudo organizado, (...) como se fosse uma empresa" (mãe C); menos tempo para dedicação profissional - duas mães (C e T) relataram esse fator. Diante disso, pode-se levar em consideração a figura da mulher contemporânea, que ocupa diversos lugares na sociedade, agregando tarefas e funções. Porém, muitas vezes acaba por sobrecarregar-se, principalmente se na dinâmica familiar ela se encontra como foco nas tarefas relacionadas ao cuidado aos filhos (Silva \& Lima, 2012). O fato de aumentar o nível de estresse e a necessidade de gerir mais conflitos entre os irmãos/ãs foi relatado por apenas uma mãe (R) e, de acordo com Dunn e Kendrick (1980 citados por Oliveira \& Lopes, 2010), as mães, nesse momento de chegada do segundo filho, passam a ter menos paciência e a tendência é de amplificar o estresse. $\mathrm{O}$ aumento do medo também foi relatado por uma mãe $(\mathrm{T})$, bem como o fato de, mesmo com todas as demandas, conseguir manejar as situações para ter um tempo para si. 
$\mathrm{Na}$ categoria desenvolvida diante do impacto no pai foram estabelecidas seis subcategorias, e nelas foram destacados aspectos como aumento da preocupação, relatado por dois pais (R e C) - "A preocupação fica mais intensa" (pai C). O aumento da autoridade e paciência foi ressaltado por um pai (R), e aumento da responsabilidade, indicado por um pai. Esses fatores relatados podem estar relacionados com o fato de que as configurações atuais de família possibilitam uma flexibilidade na maternidade e paternidade quanto aos cuidados perante os filhos e tarefas de casa, onde há uma divisão de responsabilidades (Goetz \& Vieira, 2009). Ainda foram salientados aspectos como sensação de traição em relação ao primogênito, diminuição de sono e o fato de conseguir gerir o tempo para seu próprio lazer, relatados por um pai (T). De acordo com Lamb (2010), o acontecimento de tornar-se pai é um grande marco na vida dos homens, e, dessa maneira, é gerador de diversas emoções conflituosas, como medo e alegria.

Nessa categoria, voltada para o impacto nos pais e mães em relação ao primogênito, foram analisados dados a partir da percepção dos pais e mães sobre alterações relacionais. Foram estabelecidas três subcategorias, que destacaram aspectos como maior proximidade do pai com o primogênito, fato este relatado por dois casais $(\mathrm{C}$ e $\mathrm{T})$. Um dos casais (R) relatou que não observou mudança acerca de quem ficava mais tempo com o primogênito - "Foi natural, acho que não houve diferença porque a gente trabalha no mesmo horário" (mãe R). Deutsch (2001) e Crepaldi, Andreani, Hammes, Ristof, \& Abreu (2006) relatam que quando a mãe se dispõe totalmente aos cuidados dos filhos, em geral há um aumento de responsabilidades, porém quando a mãe permite o acesso do pai, dividindo as exigências, o tira de uma posição de coadjuvante e torna-o companheiro no processo. Um casal (R) fez o apontamento sobre o aspecto de conversar mais com o primogênito mais do que brincar com ele. Pereira e Piccinini (2011) relatam que, com a chegada de um novo filho, surgem mudanças na forma com que os pais e mães se relacionam com o primogênito, o que faz o estilo parental ter o papel de mediar tanto positivamente como negativamente a relação.

A partir do que foi discorrido no eixo III, as mães acabam por exigir mais de si com a chegada do segundo filho, diminuindo a dedicação profissional pelo excesso de demandas. Para os pais, a informação mais recorrente foi o aumento de preocupação com a família, deixando-os mais protetores em relação aos filhos e às esposas. Quanto à relação genitores-primogênito, pode-se perceber que os pais se aproximaram mais do filho mais velho, e investiram mais no diálogo com ele, podendo esses fatores estarem associados às estratégias de manejo frente a esse período de mudança na dinâmica familiar.

Eixo IV - Estratégias de manejo referentes às mudanças a partir chegada do segundo filho

No eixo IV, focalizou-se nas estratégias de manejo adotadas pelos casais, divididas em duas categorias: estratégias de manejo adotadas em relação ao primogênito, visando à melhor adaptação deste no momento de chegada do irmão ou irmã; e estratégias utilizadas pelo casal visando à qualidade da relação conjugal (QUADRO 2). 
Quadro 2 - Estratégias de Manejo

\begin{tabular}{|c|c|c|}
\hline Categorias & Subcategorias & Casais \\
\hline \multirow{5}{*}{$\begin{array}{l}\text { Em relação ao } \\
\text { primogênito }\end{array}$} & $\begin{array}{l}\text { Presentear no dia do nascimento do irmão } \\
\text { mais novo na maternidade }\end{array}$ & $2(\mathrm{C} \mathrm{e} \mathrm{T})$ \\
\hline & Fazer um novo quarto para o primogênito & $2(\mathrm{C} \mathrm{e} \mathrm{T})$ \\
\hline & Incluí-lo nas tarefas relacionadas ao bebê & $2(\mathrm{C}$ e $\mathrm{R})$ \\
\hline & Colocá-lo numa arte marcial & $1(\mathrm{~T})$ \\
\hline & Investir no diálogo & $3(\mathrm{C}, \mathrm{T}$ e $\mathrm{R})$ \\
\hline \multirow{6}{*}{$\begin{array}{c}\text { Em relação } \\
\text { à Qualidade } \\
\text { da Relação } \\
\text { Conjugal }\end{array}$} & Divisão de tarefas & $3(\mathrm{C}, \mathrm{T}$ e $\mathrm{R})$ \\
\hline & Rede de apoio & $2(\mathrm{C}$ e $\mathrm{R})$ \\
\hline & Escola & $1(\mathrm{R})$ \\
\hline & Diminuir carga laboral & $1(\mathrm{~T})$ \\
\hline & Ter um tempo para o próprio lazer & $1(\mathrm{~T})$ \\
\hline & Levar as crianças junto quando saem & $2(\mathrm{C} \mathrm{e} \mathrm{T})$ \\
\hline
\end{tabular}

Fonte: Elaboração da autora (2018)

A partir da análise do Quadro 2, pode-se perceber que a estratégia mais utilizada em relação ao primogênito foi a de investir no diálogo, a fim de explicar as situações e incluí-lo nesse momento de mudança - "Ela (P) me perguntou por que tu veste ele (S), e eu não, e eu respondi você é uma mocinha, ele ainda nem sabe falar direito daqui a pouco ele vai aprender a fazer sozinho como você, você também já foi assim" (mãe R). Os autores Walz e Rich (1983) relatam que, com a chegada do segundo filho, as mães principalmente doam bastante tempo para interagir com o primogênito, buscando favorecer uma aceitação do mesmo com o irmão mais novo. Fazer um novo quarto para o filho mais velho também apareceu como estratégia para dois casais (C e T) para lidar com o processo. Esteves, Sonego, Vivian, Lopes, e Piccinini (2013) demonstram em seu estudo que as mães buscaram como estratégia mudanças na residência para a chegada do segundo filho, incluindo fazer um novo quarto para o primogênito. Os autores também demonstraram como estratégia a participação ativa do primogênito na preparação para a chegada do bebê (Esteves et al., 2013). $O$ fato de inclusão do primogênito nas tarefas relacionadas ao bebê foi salientado, sendo relatado por dois casais (C e R). As outras subcategorias apresentadas como: presentear o primogênito na maternidade diante da chegada do irmão mais novo teria como objetivo associar o nascimento do novo membro da família como um presente para o irmão mais velho, e o fato de colocar o primogênito numa arte marcial teria como estratégia diminuir a raiva do mesmo. Essas duas subcategorias estariam relacionadas com o apoio emocional que os pais e mães estariam buscando dar para o primogênito nesse momento de transição, o qual se refere à afeição, aprovação e preocupação com ele (Craig \& Winston, 1989).

Quanto às estratégias para qualidade da relação conjugal, a divisão de tarefas se mostrou mais presente - "A gente não tem empregada então sempre estamos dividindo tarefas, até a primogênita entrou nessa (...) incentiva a 
autonomia dela" (pai R). De acordo com Dessen (1997), quando a família aumenta, a tendência é de que pais e mães formem uma espécie de grupo de trabalho, onde há divisão de tarefas quanto aos cuidados das crianças e da casa. Foi relatada por um dos casais (C) a importância da família extensa no auxílio dos cuidados com os filhos (rede de apoio). De acordo com a literatura, a rede de apoio se mostra muito importante nesse momento, sendo que a participação mais ativa dos avós maternos, escola e pais na divisão de tarefas auxilia na diminuição de demandas (Piccinini et al., 2007). Outra subcategoria definida foi a do auxílio da escola, vista como estratégia de manejo em função de, ao deixar as crianças na escola desde cedo, fornecer um tempo livre ao casal e também para os pais e mães terem o próprio lazer, fato que tem relação direta com a rede de apoio relatada por Piccinini et al. (2007). Outra subcategoria que surgiu foi a de diminuição de carga laboral, focalizada no papel materno, onde se pode levar em consideração o cuidado com o bebê e voltar a atenção a este aspecto, visando à qualidade da relação/interação mãe-bebê. Levar as crianças junto quando saem foi outra estratégia apresentada por dois casais ( $\mathrm{C}$ e $\mathrm{T}$ ), manejo encontrado para não deixarem de realizar suas saídas - que faziam parte da rotina anteriormente.

Nesse eixo foram destacadas maneiras que os pais e mães encontraram para administrar esse momento de mudança com qualidade, tais estratégias se referem tanto para relação conjugal como para lidar com as demandas do primogênito, mas acabam por se interligar de várias formas. Os principais aspectos relatados foram de investir no diálogo com o primogênito e de divisão de tarefas entre pais e mães, sendo importantes meios para qualidade das relações e manejo das relações familiares.

\section{CONSIDERAÇÕES FINAIS}

Os estudos acerca do impacto do segundo filho nas relações familiares ainda são, em sua maioria, de origem norte-americana e apontam as manifestações comportamentais e emocionais do primogênito com a chegada de um irmão mais novo, mas carecem de uma pesquisa aprofundada a respeito das mudanças para/nos pais e mães.

$\mathrm{Na}$ presente pesquisa o impacto na relação conjugal apresentou-se como um afastamento físico dos casais em relação a momentos a dois, reforçando muitas vezes os papéis de pais e mães (Bourguignon et al., 1980 citados por Pereira \& Piccinini, 2007). Os relatos dos casais voltavam-se para questões relacionadas aos filhos, e apesar de serem questionados sobre a relação conjugal em si, acabavam por envolver a coparentalidade. Após o nascimento do segundo filho, casais referem maior satisfação na relação conjugal do que o contrário, o que pode estar relacionado com a qualidade de desenvolvimento das funções parentais e o impacto que isso pode ter sobre os casais, mesclando percepções de coesão e afeto entre a conjugalidade e a parentalidade.

Sobre as identificações de impactos no primogênito com a chegada do irmão mais novo, pode-se perceber que o aspecto mais salientado pelos pais e mães foi a questão de o primogênito buscar formas de chamar atenção dos adultos, principalmente quando o irmão recebe visitas de outras pessoas, característica relatada pelos três 
casais (C, T, e R) entrevistados. Além disso, a independência e autonomia do primogênito, e a valorização da presença/chegada do irmão mais novo, foram pouco relatadas. A literatura demonstra que primogênitos que apresentam idades mais próximas ao do segundo filho demonstram maior dificuldade de manejar a situação de mudança que lhe é apresentada. Dessa forma, comportamentos de procurar e chamar atenção dos pais podem ser vistos com mais frequência (Dunn, Kendrick, \& Mcnamee, 198, citado por Volling, 2012).

Com relação ao impacto nos genitores e na relação genitores-primogênito foi possível identificar uma maior aproximação do pai com o primogênito, fato que já foi demonstrado na literatura (Stewart et al., 1987, citados por Pereira \& Piccinini, 2007). Além disso, duas mães relataram que sentem uma necessidade maior de organização nesse momento de vida, relacionada ao acúmulo de tarefas com os cuidados dos filhos e da casa, e os pais ressaltaram um aumento de preocupação com a família em relação à proteção dos membros familiares.

Diante das estratégias encontradas pelos pais e mães nesse período de transição na família, foram destacadas a rede de apoio, onde os avós apareceram como fonte de suporte aos pais e mães, a divisão de tarefas entre o casal, aliviando as demandas para ambos, e investimento no diálogo com o primogênito a fim incluí-lo em situações que envolvem o irmão.

Foi possível discutir neste artigo aspectos relacionados ao filho mais velho com a chegada do segundo filho na família, e em como as estratégias encontradas pelos pais e mães para lidar com esse período de mudança se fazem importantes para a adaptação tanto deles próprios quanto do primogênito. Esses aspectos podem contribuir no auxílio de pais e mães a estabelecerem planejamentos saudáveis nesse período do ciclo vital, com o objetivo de priorizar os impactos positivos. Apesar dessa contribuição do estudo, apresentaram-se limitações. O fato de os casais entrevistados fazerem parte da rede interpessoal da entrevistadora pode ter interferido nas respostas, principalmente no que se refere à satisfação conjugal. Além disso, as perguntas no roteiro de entrevista que diziam respeito à relação conjugal poderiam ter sido mais exploradas, no sentido de significar a satisfação ou não do casal. Com isso, lacunas diante dos fatores emocionais relatados pelos pais e mães e enquanto casal nesse período de mudança permaneceram. Espera-se que essa discussão possa estimular pesquisas futuras que sigam por vieses diferentes, como, por exemplo, o impacto direto na relação conjugal, contribuindo para uma compreensão maior acerca do fenômeno 'impacto' nas relações familiares com a chegada do segundo filho.

\section{REFERÊNCIAS}

Adlams, W. (1985). The Missing Triad: The Case of Two-Child Families. Family Process, 24(3), 409-413.

Ariés, Pu (1977). História Social da Criança e da Família. Rio de Janeiro: Zahar.

Bardin, L. (1977). Análise de Conteúdo. Lisboa: Edições 70.

Baydar, N., Greek, A., \& Brooks-Gunn, J. (1997). A Longitudinal Study of the Effects of the Birth of a Sibling during the First 6 Years of Life. Journal of Marriage And The Family, 59(4), 939-956. 
Beltrame, G. \& Bottoli, C. (2010). Retratos do Envolvimento Paterno na Atualidade. Barbarói, 32, 205-226.

Bowlby, J. (2006). Cuidados Maternos e Saúde Mental. São Paulo: Martins Fontes.

Cardoso, J. \& Veríssimo, M. (2013). Estilos parentais e relações de vinculação. Análise Psicológica, 4(31), 393-406.

Carter, B. \& Mcgoldrick, M. (2001). As Mudanças no Ciclo de Vida Familiar: uma estrutura para a terapia familiar (2a ed.). Porto Alegre: Artmed.

Crepaldi. M. A.s Andreani, G., Hammes, P. S., Ristof, C. D., \& Abreu, S. R. (2006). A participação do pai nos cuidados da criança, segundo a concepção de mães. Psicologia em Estudo, 11(3), 579-587.

Craig, J. \& Winston, T. (1989). The effect of social support on prenatal care. The Journal of applied behavioral science, 25(1), 79-98.

Cúnico, S. \& Arpini, D. (2013). A família em mudanças: desafios para a paternidade contemporânea. Pensando Famílias, 17(1), 28-40.

Dessen, M. (1997). Desenvolvimento familiar: transição de um sistema triádico para poliádico. Temas em Psicologia, 3, 51-61.

Deutsch, F. (2001). Equally shared parenting. Current Directions in Psychological Science, 10(1), 25-28.

Dunn, J. \& Kendrick, C. (1980). The arrival of a sibling changes in patterns of interaction mother and first-born and first-born child. Journal Of Child Psychology And Psychiatry, 21(2), 119-132.

Dunn, J. \& Kendrick, C. (1986). Hermanos y hermanas: Amor, envidia y compreensión. Madrid: Alianza.

Esteves, C., Sonego, J. C., Vivian, A. G., Lopes, R. C. S., \& Piccinini, C. A. (2013). A gestação do segundo fi- lho: sentimentos e expectativas da mãe. Psico, 44(4), 542-551.

Felippi, G. \& Itaqui, L. (2015). Transformações dos laços vinculares na família: uma perspectiva psicanalítica. Pensando Famílias, 19(1), 105-113.

Field, T. \& Reite, M. (1984). Children's responses to separation from mother during the birth of another child. Child Development, 55, 1308-1316.

Goetz, E. \& Vieira, M. (2009). Percepções dos filhos sobre aspectos reais e ideais do cuidado parental. Estudos de Psicologia, 26(2), 195-203.

Gomes, L., Bossardi, C. N., Cruz, R. M., Crepaldi, M. A. \& Vieira, M. L. (2014). Propriedades psicométricas de instrumentos de avaliação do envolvimento paterno: revisão de literatura. Avaliação Psicológica: Interamerican Journal of Psychological Assessment, 13(1), 19-27.

Hansen, T. (2012). Parenthood and happiness: A review of folk theories versus empirical evidence. Social Indicators Research, 108(1), 29-64.

Lamb, M. (2010). The role of the father in child development. New York: Wiley.

Lobo, C. (2009). Parentalidade social, fratrias e relações intergeracionais nas recomposições familiares. Sociologia, Problemas e Práticas, 59, 45-74.

Oliveira, D., Pereira, C. R., Lopes, R. C. S., Bandeira, D. R., \& Piccinini, C. A. (2016). Impacto emocional da gestação materna para primogênitos em idade pré-escolar. Arquivos Brasileiros de Psicologia, 67(3), 94-111.

Oliveira, D. \& Lopes, R. (2010). Implicações emocionais da chegada de um irmão para o primogênito: uma revisão da literatura. Psicologia em Estudo (Maringá), 15(1), 97-106. 
Oliveira, N. (2009). Recomeçar: família, filhos e desafios. São Paulo: Cultura Acadêmica.

Pereira, Én, Ramos, M., \& Silveira, E. (2016). Configurações familiares e implicações para o trabalho em saúde da criança em nível hospitalar. Physis: Revista de Saúde Coletiva, 26(3), 961-979.

Pereira, C. \& Piccinini,, C. (2011). Gestação do segundo filho: percepções maternas sobre a reação do primogênito. Estudos de Psicologia, 28(1), 65-77.

Pereira, C. \& Piccinini, C. (2007). O impacto da gestação do segundo filho na dinâmica familiar. Estudos de Psicologia, 24(3), 385-395.

Piccinini, C. A., Pereira, C. R. R., Marin, A. H., Lopes, R. C. S., \& Tudge, J. (2007). $\mathrm{O}$ nascimento do segundo filho e as relações familiares. Psicologia: Teoria e Pesquisa, 23(3), 253-262.

Pollmann-Schult, M. (2014). Parenthood and life satisfaction: why don't children make people happy? Journal of Marriage and Family, 76(2), 319-336.

Pontes, F., Silva, S. S. C., Garotti, M., \& Magalhães, C. M. C. (2007). Teoria do apego: elementos para uma concepção sistêmica da vinculação humana. Aletheia, 26, 67-79.

Rocha-Coutinho, M. (2015). Investimento da mulher no mercado de trabalho: repercussões na família e nas relações de gênero. In T. Féres-Carneiro (Org.), Família e casal: parentalidade e filiação em diferentes contextos (pp. 103-118). Rio de Janeiro: Prospectiva \& PUC.

Rolim, K. I. \& Wendling, M. I. (2013). A história de nós dois: reflexões acerca da formação e dissolução da conjugalidade. Psicologia Clínica, 25(2), 165-180.

Scaglia, A., Mishima-Gomes, F., \& Barbieril, V. (2018). Paternidade em diferentes configurações familiares e o desenvolvimento emocional da filha. Psico-USF, 23(2), 267-278.

Scavone, L. (2001). Maternidade: transformações na família e nas relações de gênero. Interface - Comunicação, Saúde, Educação, 5(8), 47-59.

Scorsolini-Comin, F. \& Santos, M. A. (2010). Satisfação conjugal: revisão integrativa da literatura científica nacional. Psicologia: Teoria e Pesquisa, 26(3), 525532. https://dx.doi.org/10.1590/ $\underline{\text { S0102-37722010000300015 }}$

Silva, M., Bueno, M., \& Ribeiro, J. (2014). A percepção dos pais frente ao desenvolvimento nas atividades com o (s) filho (s). Revista Gaúcha, 35(1), 14-21.

Silva, M. \& Lima, A. (2012). Mulher, trabalho e família na cena contemporânea. Contextos Clínicos, 5(1), 45-51.

Staudt, A. \& Wagner, A. (2008). Paternidade em tempos de mudança. Psicologia: Teoria e Prática, 10(1), 174-185.

Stewart, R. B., Mobley, L. A., Van-Tuyl, S. S., \& Salvador, M. A. (1987). The firstborn's adjustment to the birth of a sibling: a longitudinal assessment. Child Development, 58(2), 341-355.

Volling, B. (2012). Family transitions following the birth of a sibling: An empirical review of changes in the firstborn's adjustment. Psychological bulletin, 138(3), 497-528.

Walsh, F: (2012). Normal family processes: Growing diversity and complexity. New York: Guilford Press.

Walsh, F. (2016). Processos Normativos da Família: diversidade e complexidade. Porto Alegre: Artmed.

Walz, B. \& Rich, 0. (1983). Maternal tasks of taking-on a second child in the postpartum period. Journal Matern Child Nurs, 12(3), 185-216. 
BIBIANA UGHINI GOLDSCHMIDT

É psicóloga e psicoterapeuta. Graduada em Psicologia (UNISUL), pós-graduanda em Avaliação Psicológica (IPOG) e em formação plena em Gestalt-terapia (Instituto Granzotto de Psicologia).

E-mail: psicologiabibiana@gmail.com

Nova Perspectiva Sistêmica, n. 65, p. 036-050, dezembro 2019. 